\title{
In Situ Formation of Ti47Cu38Zr7.5Fe2.5Sn2Si1Nb2 Amorphous Coating by Laser Surface Remelting
}

\author{
Peizhen Li, Lingtao Meng, Shenghai Wang *, Kunlun Wang, Qingxuan Sui, Lingyu Liu, \\ Yuying Zhang, Xiaotian Yin, Qingxia Zhang and Li Wang *
}

School of Mechanical, Electrical \& Information Engineering, Shandong University (Weihai), Weihai 264209, China; peizhenl@yeah.net (P.L.); mlt142536@163.com (L.M.); wkl@sdu.edu.cn (K.W.);

qingxuansui@163.com (Q.S.); 110241ly@163.com (L.L.); zyy741790710@163.com (Y.Z.);

15262019723@163.com (X.Y.); 17862703363@163.com (Q.Z.)

* Correspondence: shenghaiw@163.com (S.W.); wanglihxf@sdu.edu.cn (L.W.);

Tel.: +86-631-568-8224 (S.W. \& L.W.)

Received: 21 October 2019; Accepted: 4 November 2019; Published: 7 November 2019

\begin{abstract}
In previous studies, Ti-based bulk metallic glasses (BMGs) free from $\mathrm{Ni}$ and Be were developed as promising biomaterials. Corresponding amorphous coatings might have low elastic modulus, remarkable wear resistance, good corrosion resistance, and biocompatibility. However, the amorphous coatings obtained by the common methods (high velocity oxygen fuel, laser cladding, etc.) have cracks, micro-pores, and unfused particles. In this work, a Ti-based Ti47Cu38Zr7.5Fe2.5Sn2Si1Nb2 amorphous coating with a maximum thickness of about $100 \mu \mathrm{m}$ was obtained by laser surface remelting (LSR). The in-situ formation makes the coating dense and strongly bonded. It exhibited better corrosion resistance than the matrix and its corrosion mechanism was discussed. The effects of LSR on the microstructural evolution of Ti-based prefabricated alloy sheets were investigated. The nano-hardness in the heat affected zone (HAZ) was markedly increased by $51 \%$, meanwhile the elastic modulus of the amorphous coating was decreased by $18 \%$. This demonstrated that LSR could be an effective method to manufacture the high-quality amorphous coating. The in-situ amorphous coating free from $\mathrm{Ni}$ and Be had a low modulus, which might be a potential corrosion-resistant biomaterial.
\end{abstract}

Keywords: in situ amorphous coating; laser surface remelting; Ti-based alloy

\section{Introduction}

Ti-based alloys are widely used in dental implants and orthopedic prostheses because of their high corrosion resistance and good biocompatibility. However, the elastic modulus of the alloy implant is greater compared with that of bone, causing stress shielding and bone resorption, which ultimately leads to implant failure [1]. To meet the requirements of replacing bones, developing metallic materials with high strength, low elastic modulus, high wear and corrosion resistance, and good biocompatibility is desired [2-4]. Ti-based bulk metallic glasses (BMGs) have potential applications in biomedical fields due to their low density, high specific strength, good corrosion resistance, and excellent biocompatibility, etc. [5,6]. However, the application of BMGs is very difficult, for one reason, the preparation of amorphous alloy requires cooling the molten metal liquid at an extremely fast quenching rate $\left(\sim 10^{5} \mathrm{~K} / \mathrm{s}\right)$, where the larger the workpiece, the harder to achieve. Otherwise the material will crystallize and lose the remarkable properties of the amorphous. In the Ti-based BMGs, a high content of Be (a toxic element) and Pd (an expensive metal element) are often added to maximize the glass forming ability (GFA), which confines the application of Ti-based BMGs as a biomaterial [6,7]. In this situation, if an amorphous coating can be prepared on the surface of a 
bulk material, it is possible to obtain significant surface corrosion resistance, wear resistance, and biological adhesion. We no longer consider whether the substrate is completely amorphous, because only the surface properties of the material are considered. Common methods for preparing amorphous coatings are high velocity oxygen fuel (HVOF) [8], laser cladding [9], ion bombardment [10], surface mechanical attrition treatment (SMAT) [11], etc. The coatings obtained by ion bombardment and SMAT are nanoscale, which is easily broken down by abrasion and usually has partial crystallization. The coatings prepared by HVOF and laser cladding are completely amorphous, but have a large number of cracks, micro-pores, and unfused particles, which greatly reduces their immersion corrosion resistance [12]. The in situ formation method might form a coating without these defects. Laser surface remelting (LSR) is accompanied by an instantaneous cooling rate on the order of $10^{5}-10^{8} \mathrm{~K} / \mathrm{s}$, which is considered to be a more effective method for the surface modification of titanium alloys $[13,14]$. To date, studies of laser surface modification have usually focused on refining grains and obtaining crystal phases $[14,15]$. We believe that LSR may be a potential method for preparing amorphous coatings due to its fast cooling rate, ease of changing process parameters, and low cost.

In previous studies, it was found that Ti-based BMGs free from $\mathrm{Ni}$ and Be can be formed in a $\mathrm{Ti}-\mathrm{Cu}-\mathrm{Zr}-\mathrm{Fe}-\mathrm{Sn}-\mathrm{Si}$ alloy system. This is considered to be promising for biomedical applications $[16,17]$. We added a small amount of $\mathrm{Nb}$ element to this system to improve the corrosion resistance of the alloy [18]. A high $\mathrm{Nb}$ element content will reduce the GFA of the system. Finally, we chose a nominal composition of Ti47Cu38Zr7.5Fe2.5Sn2Si1Nb2 (at. \%) as the subject. We intended to develop an amorphous coating with notable corrosion resistance and potential bio-application prospects.

In the present work, LSR was conducted for a prefabricated Ti-based alloy sheet with the laser-induced microstructures and phase changes carefully characterized by back-scattered electron (BSE) imaging and $x$-ray diffraction (XRD) techniques. In addition, hardness variation across the laser modified zones was examined, and corrosion resistance was also analyzed by anodic polarization experiments.

\section{Materials and Methods}

Alloy ingots with a nominal composition of Ti47Cu38Zr7.5Fe2.5Sn2Si1Nb2 (at. \%) were prepared by arc-melting the mixture of the pure elements under a high-purity argon atmosphere. The intermediate alloy was melted five times to ensure the uniformity of ingredients. Plate samples with thicknesses of $2 \mathrm{~mm}, 1.5 \mathrm{~mm}$, and $1 \mathrm{~mm}$ were fabricated by suction casting with water cooled copper molds. The surface of the specimens was polished to 3000-grit by silicon carbide paper and cleaned by absolute ethanol. The laser surface remelting (LSR) experiment was carried out under the protection of a flowing high-purity argon atmosphere, accomplished by a commercial selective laser melting machine (SLM Solutions 125HL, Lubeck, Germany) equipped with a $1067 \mathrm{~nm}$ wavelength fiber laser of up to $400 \mathrm{~W}$ laser power with a beam diameter of about $80 \mu \mathrm{m}$. The surface of the melt receives the effect of spheroidization, causing uneven surface topography (Figure 1a). Figure $1 \mathrm{~b}$ shows the scheme of the LSR experiment.

The linear energy density (LED), as the single line effective energy input during LSR, can be calculated by $\mathrm{P} / \mathrm{v}(\mathrm{J} / \mathrm{mm})[19,20]$. P represents the laser power and $\mathrm{v}$ represents the scanning speed. In this paper, scanning speed (v) was $2000 \mathrm{~mm} / \mathrm{s}$, hatch distance (h) was $140 \mu \mathrm{m}$, and laser powers (P) were $0 \mathrm{~W}, 140 \mathrm{~W}, 160 \mathrm{~W}, 180 \mathrm{~W}, 200 \mathrm{~W}, 220 \mathrm{~W}, 240 \mathrm{~W}, 260 \mathrm{~W}, 280 \mathrm{~W}, 300 \mathrm{~W}$, and $320 \mathrm{~W}$. All combinations of different thicknesses of samples and laser powers were processed three times to ensure repeatability. The structures of the treated samples were conducted via x-ray diffraction (XRD, Ultima IV, Rigaku, Tokyo, Japan) with $\mathrm{Cu} K \alpha$ radiation. The nanoindentation characteristics of the sample cross sections were acquired by a Nano Indenter NHT2 (Anton Paar, Austria). The maximum load was $15 \mathrm{mN}$, and the loading speed was $30 \mathrm{mN} / \mathrm{min}$. Microstructural characteristics under laser treatment were investigated by scanning electron microscopy (SEM, Nova Nano SEM450, FEI Sirion, Hillsboro, OR, USA). To evaluate the corrosion resistance, anodic polarization experiments were implemented in $3.5 \mathrm{wt}$. \% $\mathrm{NaCl}$ aqueous solution at room temperature. 

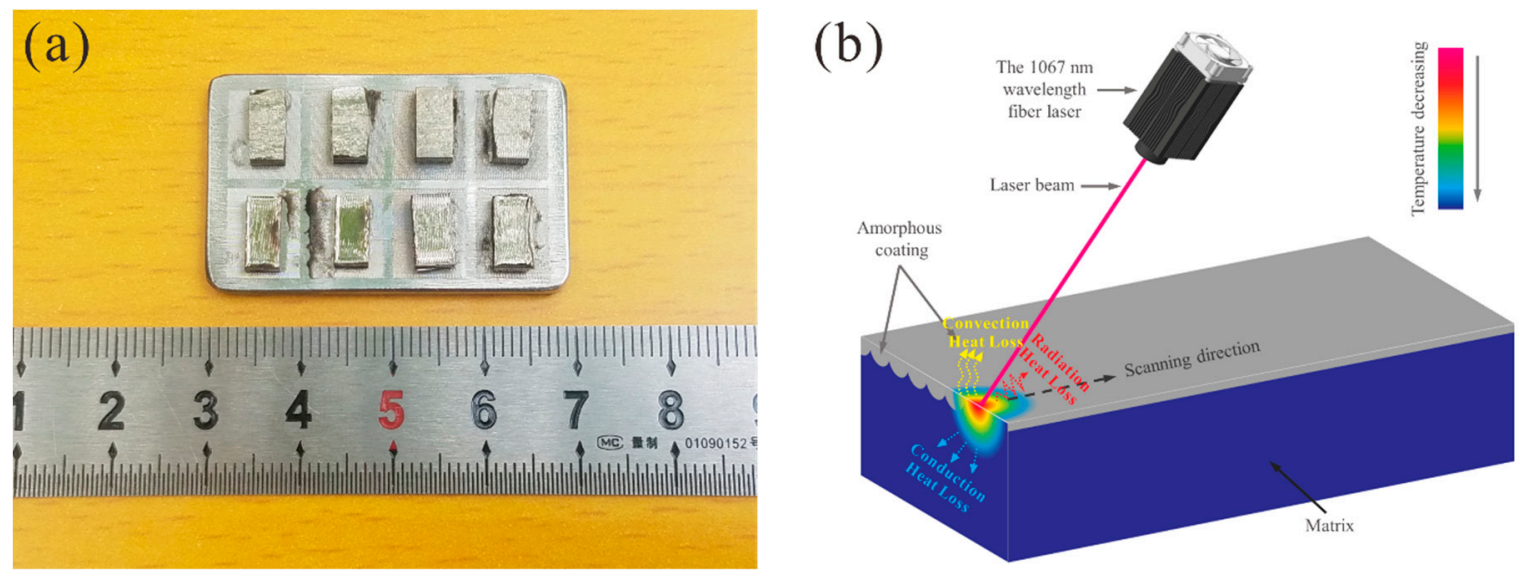

Figure 1. (a) The plate samples disposed by different laser powers; (b) Scheme of the laser surface remelting.

\section{Results and Discussion}

XRD patterns of the Ti-based alloy plates treated with different laser powers are shown in Figure 2. All diffraction peaks of the untreated samples with a thickness of $2 \mathrm{~mm}$ matched $\mathrm{CuTi}_{2}, \mathrm{CuTi}$, and $\mathrm{Cu}_{4} \mathrm{Ti}_{3}$ phases. Similar to the treatment with $200 \mathrm{~W}(\mathrm{LED}=0.10 \mathrm{~J} / \mathrm{mm})$, the $240 \mathrm{~W}(\mathrm{LED}=0.12 \mathrm{~J} / \mathrm{mm})$ exhibited a main halo without any Bragg peaks in the XRD pattern, indicating the amorphous structure. The tight combination of the melt and the solid matrix causes rapid heat extraction during solidification, allowing the melt to form a metallic glass under very high cooling rates on the order of $10^{5}-10^{8} \mathrm{~K} / \mathrm{s}[14]$. For the $280 \mathrm{~W}, \mathrm{LED}=0.14 \mathrm{~J} / \mathrm{mm}$, sharp peaks corresponding to intermetallic compounds $\mathrm{CuTi}_{2}$ and CuTi superimposed on the broad peak of amorphous phase were observed (Figure 2a).
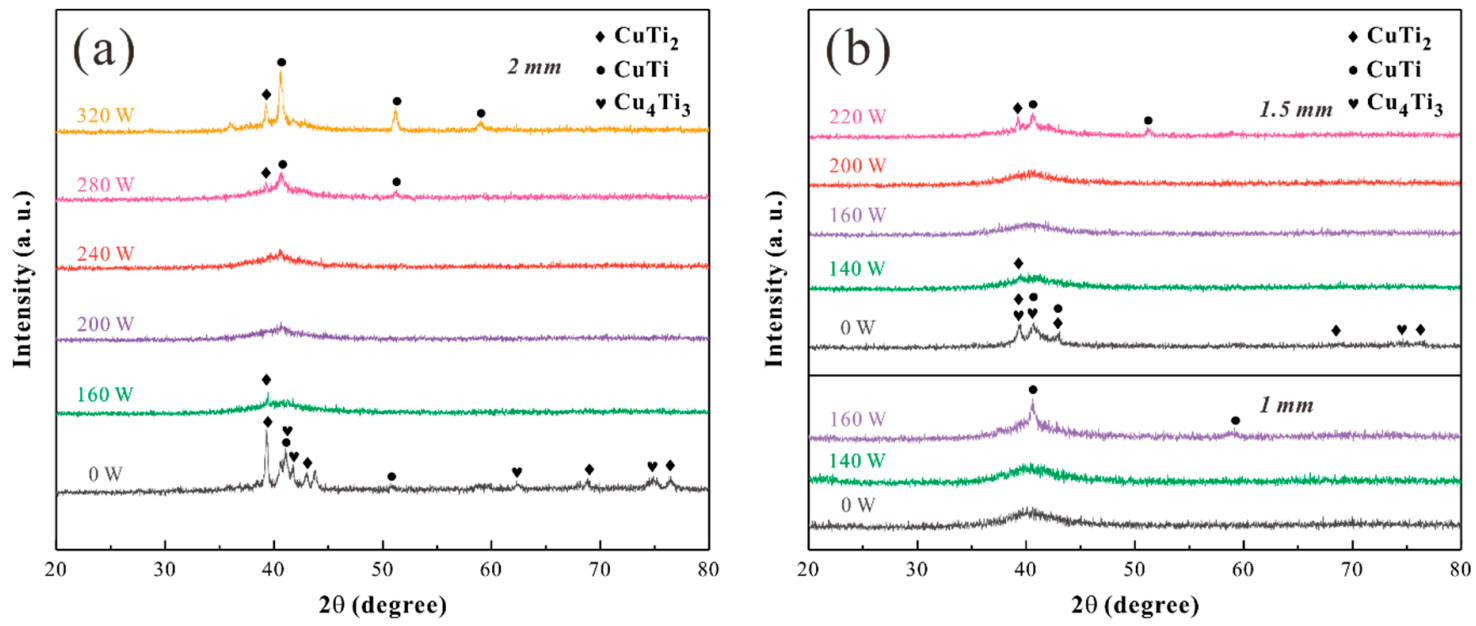

Figure 2. X-ray diffraction (XRD) patterns of samples with (a) $2 \mathrm{~mm}$ treated under different laser powers; (b) $1.5 \mathrm{~mm}$ and $1 \mathrm{~mm}$ treated under different powers.

The raw samples with a thickness of $1.5 \mathrm{~mm}$ had more nanocrystalline structure inside than the $2 \mathrm{~mm}$ samples. The nanocrystalline structure was closer to the long-range disorder than the dendrites of the matrix, which had a higher entropy value [21]. From a thermodynamic point of view, the high-conflict atom stacking arrangement corresponded to the "high-entropy" property, and makes the Gibbs free energy drop faster with decreasing temperature, which is conducive to the formation of amorphous structures during solidification. In addition, the laser heat melts the titanium plate during LSR. The generated heat can be dissipated by convection, radiation, and the material itself in a conduction way during remelting [15], while conduction heat loss in a dominant manner (see the blue arrow in Figure 1b). Thick critical dimension heats up more slowly when subjected to the same amount 
of conduction heat, resulting in a larger temperature gradient, which contributes to achieving a higher cooling rate. Therefore, the crystal in the sample of $1 \mathrm{~mm}$ was induced at a lower critical power $(160 \mathrm{~W}$, Figure $2 \mathrm{~b}$ ) than the $2 \mathrm{~mm}$ sample ( $280 \mathrm{~W}$, Figure $2 \mathrm{a}$ ) and the $1.5 \mathrm{~mm}$ sample ( $220 \mathrm{~W}$, Figure $2 \mathrm{~b}$ ).

Figure $3 a$ is the SEM image of the untreated alloy in backscattered electron (BSE) mode, showing two regions with different morphologies. The surface of the sample was obtained at a faster cooling rate to form a uniform nanocrystal, and the black dendrites were continuously grown due to the slower cooling rate inside. In Figure 3b, the material in the bright region has undergone laser remelting and re-solidification to form an amorphous coating (AC) with a maximum thickness of about $100 \mu \mathrm{m}$. There was another modification zone labeled as the heat affected zone (HAZ) beneath the AC. It can be seen that the microstructure of the heat-affected zone is similar to the surface structure in Figure $3 \mathrm{a}$, consisting of uniformly fine nanocrystals. This illustrates the proximity of the HAZ cooling rate to the water-cooled copper mold. After the LSR treatment, the fine and uniform nanocrystalline structure begins to grow under the thermal effect, and grows radially as the dominant form of dark nanocrystals (Figure 3c, inset). Since the nanocrystals have a large atomic diffusion activation energy, the atomic co-diffusion ability is reduced. With the influence of laser heat, the atomic diffusion coefficient increases, and solute redistribution occurs further between dendrites. Ti atoms are enriched in the dark dendritic region, and $\mathrm{Zr}$ elements appear in a large number of light regions (Figure 3f). The nanocrystalline structure is gradually consumed as the dendrite grows. Randomly occurring radial dendrites are interconnected (Figure $3 \mathrm{c}$ inset), forming directional large-sized dendrite crystals (Figure 3d). The dendrites at the junction grow perpendicular to the interface, consistent with the direction in which the temperature gradient increases (see the red arrow in Figure 3a,b). There were more nanocrystals and few dendrite crystals in the initial state of the $1.5 \mathrm{~mm}$ sample (Figure 3e, inset). The temperature gradient of $160 \mathrm{~W}$ laser treatment was significantly lower than that of the $200 \mathrm{~W}$ sample. The energy density was also relatively low, so the radial dendrites had just been induced to form and cannot continue to grow, which is why it does not have a distinct HAZ region (Figure 3e). It can be seen that the dark dendritic crystal is randomly distributed in the matrix (Figure 3d), with the characteristic size of 100 to $300 \mu \mathrm{m}$. In combination with the results of XRD and Energy-dispersive $X$-ray spectroscopy (EDX), the dark phase was characterized to be primary $\mathrm{Cu}_{4} \mathrm{Ti}_{3}$, and the white regions were $\mathrm{Zr}$-rich, Sn-rich intermetallic compounds with a low melting point.

Figure $4 \mathrm{a}$ shows the measured load-displacement curves for the matrix, HAZ, and AC regions in the sample with a thickness of $1.5 \mathrm{~mm}$ under $200 \mathrm{~W}$. The corresponding experimental data are given in Table 1. The indentation hardness (HIT) of the matrix, AC, and HAZ are 7995.1, 8514.4, and $12,083 \mathrm{MPa}$, respectively. The effective elastic modulus in the different regions were obtained based on the obtained indenter's elastic modulus and Poisson's ratio, A and S values (Table 1). The effective elastic modulus was $151.78 \mathrm{GPa}$ in the matrix region, $125.55 \mathrm{GPa}$ in the AC, and $153.59 \mathrm{GPa}$ in the HAZ. The intrinsic microstructural origin for the plasticity of amorphous alloys is related to the features of the flow units. In amorphous alloys, the nanoscale liquid-like region (flow units) exhibits a lower atomic bulk density, higher energy states, easier shear deformation, and easier flow than the surrounding area [22-24]. The existence of large free volume in amorphous alloys increases the interatomic distance, weakening the atomic bonding energy and atomic migration barrier, resulting in a decrease in hardness and elastic modulus [25]. The load-displacement curve of the AC shows a prominent trait of the intermittent plastic deformation, termed serration or serrated flow [26]. It is generally accepted that the deformation mechanism for amorphous alloys is the nucleation and expansion of shear bands. In our load-controlled tests, the operation of a shear band gives rise to a burst of displacement [27]. Since a serrated flow seems to correspond to each shear band, we expect that larger plastic deformation originates in the accumulation of single shear displacements $[27,28]$. The distribution of effective elastic modulus from the AC to the matrix region in a sample with thickness of $2 \mathrm{~mm}$ under $200 \mathrm{~W}$ is illustrated in Figure $4 \mathrm{~b}$. Nanoindentation experiments were performed three times for the samples to ensure repeatability. The distribution of the effective elastic modulus in different regions showed the same trend. Furthermore, the effective elastic modulus in the AC zone (123.22 $\pm 4.64 \mathrm{GPa})$ was clearly lower 
than that in the matrix region (149.03 \pm 5.76 GPa) and HAZ (153.22 \pm 3.96 GPa). The nano-hardness of the $2 \mathrm{~mm}$ samples treated by $200 \mathrm{~W}$ in the HAZ $(10.035 \pm 1.45 \mathrm{GPa})$ was higher than that in the matrix region $(8.381 \pm 0.279 \mathrm{GPa})$ and $\mathrm{AC}$ zone $(8.082 \pm 0.396 \mathrm{GPa})$. Microscopic examination revealed that nanocrystalline dispersion would provide effective precipitation strengthening. Since the structure of nanocrystalline has a short average interatomic distance and strong atomic bonding due to the annihilation of free volume, it has the highest hardness and modulus of elasticity [29].
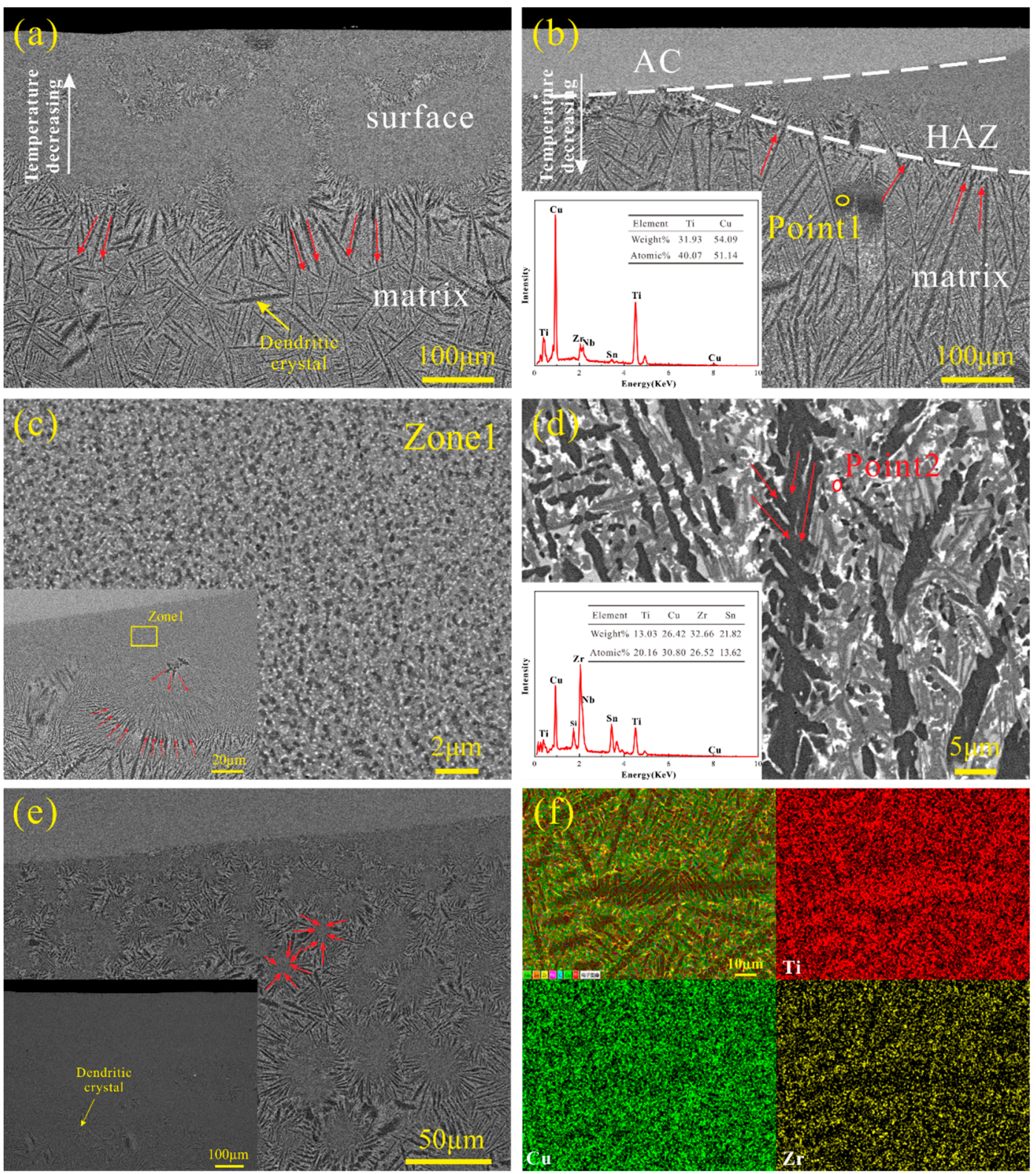

Figure 3. Back-scattered scanning electron microscopy (SEM) micrographs of the (a) cross-section of the $2 \mathrm{~mm}$ Ti alloy untreated; (b) the $2 \mathrm{~mm}$ sample under $200 \mathrm{~W}$ and the Energy-dispersive X-ray spectroscopy (EDX) corresponding to point 1; (c) Heat affected zone (HAZ); and (d) matrix regions in the sample with $2 \mathrm{~mm}$ under $200 \mathrm{~W}$ at high magnification and the EDX of point 2; (e) the $1.5 \mathrm{~mm}$ sample under $160 \mathrm{~W}$ with the inset showing untreated; (f) SEM-EDX mapping of dendritic crystals in sample with $2 \mathrm{~mm}$ under $200 \mathrm{~W}$. 

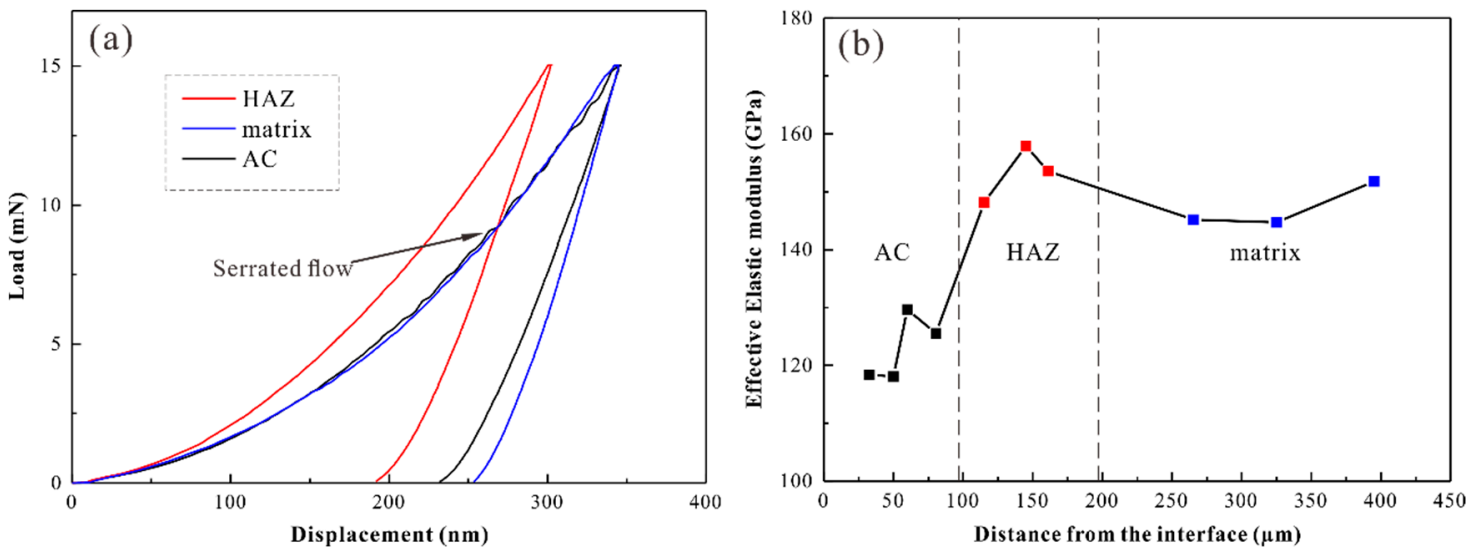

Figure 4. (a) Load-displacement curve in different regions of the $1.5 \mathrm{~mm}$ sample by $200 \mathrm{~W}$; (b) Effective elastic modulus in the different regions near the surface of the $2 \mathrm{~mm}$ sample by $200 \mathrm{~W}$.

Table 1. Nano-hardness and elastic modulus in the different zones of the $1.5 \mathrm{~mm}$ sample by $200 \mathrm{~W}$.

\begin{tabular}{cccc}
\hline Test Parameters & HAZ & Matrix & AC \\
\hline Maximum load $\left(\mathrm{P}_{\max }, \mathrm{mN}\right)$ & 15 & 15 & 15 \\
Indenter's Poisson's ratio & 0.07 & 0.07 & 0.07 \\
Indenter's elastic modulus $(\mathrm{GPa})$ & 1141 & 1141 & 1141 \\
Contact depth $\left(\mathrm{h}_{\mathrm{c}}, \mathrm{nm}\right)$ & 231.93 & 288.88 & 279.59 \\
Contact area $\left(\mathrm{A}, \mathrm{nm}^{2}\right)$ & $1,244,136.48$ & $1,878,274.12$ & $1,763,841.78$ \\
Contact stiffness $\left(\mathrm{S}, \mathrm{mN}^{2} \mathrm{~nm}\right)$ & 0.1763 & 0.2143 & 0.1753 \\
Nano-hardness $(\mathrm{H}, \mathrm{GPa})$ & 12.083 & 7.9951 & 8.5144 \\
Effective Elastic modulus $\left(\mathrm{E}^{*}, \mathrm{GPa}\right)$ & 153.59 & 151.78 & 125.55 \\
\hline
\end{tabular}

The anodic polarization curve for the in situ Ti-based amorphous coating in a $3.5 \% \mathrm{NaCl}$ solution at room temperature in open air, and the curve for specimens deposited under different laser powers are also presented for comparison, as shown in Figure 5. All the anodic portions of the polarization curves exhibit atypical passivation behavior. The corrosion current density $\left(\mathrm{I}_{\text {corr }}\right)$ values of all the specimens are shown in the inset image of Figure 5. The $I_{\text {corr }}$ value of $240 \mathrm{~W}$ was $1.78 \times 10^{-6} \mathrm{~A} / \mathrm{cm}^{2}$, which was about $15 \%$ lower than that of the untreated sample $\left(2.12 \times 10^{-6} \mathrm{~A} / \mathrm{cm}^{2}\right)$. Furthermore, the $\mathrm{I}_{\text {corr }}$ value of $200 \mathrm{~W}$ was $1.80 \times 10^{-6} \mathrm{~A} / \mathrm{cm}^{2}$, which was about $27 \%$ lower than that of the $320 \mathrm{~W}$ $\left(2.45 \times 10^{-6} \mathrm{~A} / \mathrm{cm}^{2}\right)$. According to previous studies, the remarkable corrosion resistance of metallic glasses is contributed by the composition homogeneity with low residual stresses and single-phase nature without grain boundaries and second-phase particles [30-33]. Ti and $\mathrm{Zr}$ are considered to play an important role in corrosion resistance. $\mathrm{Zr}$, Ti, and $\mathrm{Nb}$ elements have strong affinity to oxygen, thus, they easily form $\mathrm{ZrO}_{2}, \mathrm{TiO}_{2}$, and $\mathrm{Nb}_{2} \mathrm{O}_{5}$ on the surface of samples after polarization, preventing the direct contact of the corrosive solution with the alloy and thus reducing dissolution of the alloy elements (especially $\mathrm{Cu}$ ) [34]. Therefore, the existence of a large amount of $\mathrm{Ti}$ and $\mathrm{Zr}$ in the material leads to a decrease in corrosion current density. However, the $\mathrm{Cu}$ element in the $\mathrm{Cu}$-rich region reacts with chloride ions to form $\mathrm{CuCl}$, which subsequently hydrolyzes to $\mathrm{Cu}_{2} \mathrm{O}$. It provides a galvanic coupling effect for the rapid local dissolution of the $\mathrm{Zr}$-rich and Ti-rich nanometer active regions on the surface of the sample. These active metals also react with the solution, further inducing the formation of local galvanic cells involving $\mathrm{Cu}$ [35]. A similar galvanic coupling effect has also been mentioned in another study [18]. In that paper, the addition of the $\mathrm{Nb}$ element induced a dual structure containing $\mathrm{Ti} / \mathrm{Zr} / \mathrm{Nb}$-rich crystalline dendrites and amorphous matrix phases. Regarding the preferential corrosion of the amorphous matrix derived from the formation of a micro galvanic cell between the amorphous matrix and dendrite phases, the results were attributed to the difference in elemental content. In this work, however, the crystalline structure with elemental segregation formed an amorphous coating under laser induction. The amorphous coating has no elemental segregation 
zone, which is immune to the local dissolution and typically does not form undesirable heterogeneous galvanic cells. Additionally, the addition of $\mathrm{Nb}$ promotes the formation of more oxides on the surface, preventing further corrosion of the material.

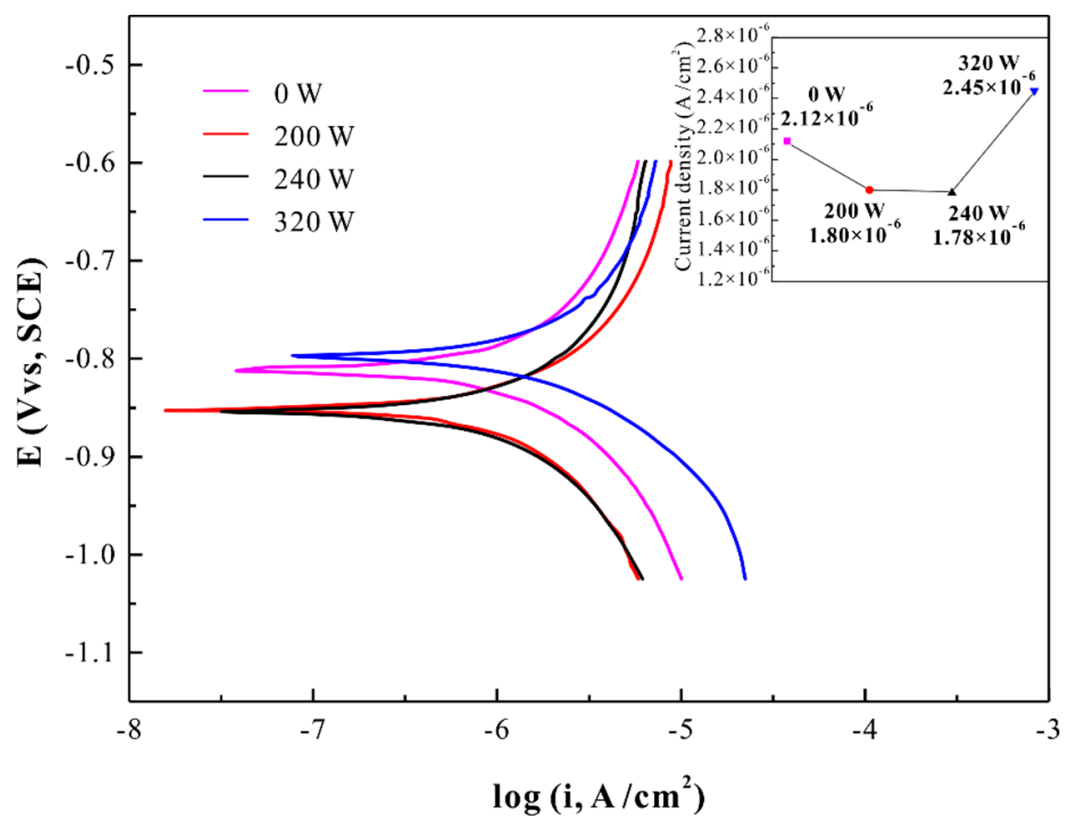

Figure 5. Anodic polarization curves and corrosion current density for the samples with a thickness of $2 \mathrm{~mm}$ deposited under different laser powers in a $3.5 \% \mathrm{NaCl}$ solution.

\section{Conclusions}

In this paper, the prefabricated alloy plate (Ti47Cu38Zr7.5Fe2.5Sn2Si1Nb2) was processed by laser surface remelting (LSR) technology to obtain an in situ, strongly binding amorphous coating. The in situ formation method makes the coating free from cracks, micro-pores, and unfused particles. The completely amorphous coatings can be obtained with the line energy density (LED) of 0.1 to $0.12 \mathrm{~J} / \mathrm{mm}$ in $2 \mathrm{~mm}$ samples. The corresponding LED was 0.08 to $0.1 \mathrm{~J} / \mathrm{mm}$ in $1.5 \mathrm{~mm}$ samples. By performing the LSR with $\mathrm{P}=200 \mathrm{~W}, \mathrm{v}=2000 \mathrm{~mm} / \mathrm{s}$, two distinct modification zones were obtained. The superior hardness promotion (by 51\%) was obtained in the heat affect zone (HAZ), and a marked decrease (by 18\%) of the elastic modulus in the amorphous coating zone (AC) was present. After the polarization, the addition of the $\mathrm{Nb}$ element to form an oxide prevented further corrosion of the material. The amorphous structure without element segregation leads to the failure of micro galvanic cells formation. In addition, the corrosion current density $\left(\mathrm{I}_{\text {corr }}\right)$ of the amorphous coating was about $15 \%$ lower than that of the untreated specimen $\left(2.12 \times 10^{-6} \mathrm{~A} / \mathrm{cm}^{2}\right)$. Therefore, the in situ amorphous coating obtained by LSR has relatively remarkable corrosion resistance. The composition free from $\mathrm{Ni}$ and Be ensures non-toxicity for biological applications. A low modulus of the coating can be better matched to the bone. This might be helpful for the development of corrosion resistant biomaterials.

Author Contributions: Conceptualization, S.W.; Methodology, P.L., X.Y., S.W., and K.W.; Software, P.L. and Q.S.; Validation, P.L., S.W., and L.W.; Formal analysis, P.L., L.M., X.Y., L.L., Y.Z., and Q.Z.; Investigation, P.L. and K.W.; Resources, S.W. and L.W.; Data curation, L.M., P.L., K.W., Y.Z., and Q.Z.; Writing-original draft preparation, P.L.; Writing-review and editing, P.L., L.M. and S.W.; Visualization, P.L. and Q.S.; Supervision, S.W.; Project administration, S.W. and L.W.; Funding acquisition, S.W. and L.W.; all authors gave their final approval.

Funding: This work was financially supported by the Natural Science Foundation of Shandong Province (no. ZR2019MEM040).

Acknowledgments: The authors are grateful to Jun Mi (Experimentalist), Qiuhong Huo (Experimentalist), Yanqing Xin (Experimentalist), and Kunlun Wang (Experimentalist) for their technical assistance. The authors are also grateful for the Physical-Chemical Test and Analysis Center of Shandong University at Weihai. 
Conflicts of Interest: The authors declare no conflicts of interest.

\section{References}

1. Geetha, M.; Singh, A.K.; Asokamani, R.; Gogia, A.K. Ti based biomaterials, the ultimate choice for orthopaedic implants-A review. Prog. Mater. Sci. 2009, 54, 397-425. [CrossRef]

2. Inoue, A. Stabilization of metallic supercooled liquid and bulk amorphous alloys. Acta Mater. 2000, 48, 279-306. [CrossRef]

3. Chen, M. A brief overview of bulk metallic glasses. Npg Asia Mater. 2011, 3, 82-90. [CrossRef]

4. WWang, H.; Dong, C.; Shek, C.H. Bulk metallic glasses. Mater. Sci. Eng. R 2004, 44, 45-89. [CrossRef]

5. Chen, Q.; Thouas, G.A. Metallic implant biomaterials. Mater. Sci. Eng. R 2015, 87, 1-57. [CrossRef]

6. Hanawa, T. Research and development of metals for medical devices based on clinical needs. Sci. Technol. Adv. Mater. 2012, 13, 064102. [CrossRef]

7. Wang, T.; Wu, Y.D.; Si, J.J.; Cai, Y.H.; Chen, X.H.; Hui, X.D. Novel Ti-based bulk metallic glasses with superior plastic yielding strength and corrosion resistance. Mater. Sci. Eng. A 2015, 642, 297-303. [CrossRef]

8. Zhang, J.; Liu, M.; Song, J.; Deng, C.; Deng, C. Microstructure and corrosion behavior of Fe-based amorphous coating prepared by HVOF. J. Alloy. Compd. 2017, 721, 506-511. [CrossRef]

9. Huang, G.; Qu, L.; Lu, Y.; Wang, Y.; Li, H.; Qin, Z.; Lu, X. Corrosion resistance improvement of 45 steel by Fe-based amorphous coating. Vacuum 2018, 153, 39-42. [CrossRef]

10. Wan, Q.; Yang, B.; Chen, Y.M.; Liu, H.D.; Ren, F. Grain size dependence of the radiation tolerances of nano-amorphous Ti-Si-N composite coatings. Appl. Surf. Sci. 2019, 466, 179-184. [CrossRef]

11. Chen, K.; Yang, H.; Gao, J.; Yang, Y. Microstructure detection of Mg-Zi-Ti-Si amorphous composite coating prepared by SMAT. Mater. Charact. 2018, 135, 265-269. [CrossRef]

12. Bai, Y.; Li, X.; Xing, L.; Wang, Z.; Li, Y. A novel non-skid composite coating with higher corrosion resistance. Ceram. Int. 2017, 43, 15095-15106. [CrossRef]

13. Chai, L.; Wu, H.; Zheng, Z.; Guan, H.; Pan, H.; Guo, N.; Song, B. Microstructural characterization and hardness variation of pure Ti surface-treated by pulsed laser. J. Alloy. Compd. 2018, 741, 116-122. [CrossRef]

14. Yao, Y.; Li, X.; Wang, Y.Y.; Zhao, W.; Li, G.; Liu, R.P. Microstructural evolution and mechanical properties of Ti-Zr beta titanium alloy after laser surface remelting. J. Alloy. Compd. 2014, 583, 43-47. [CrossRef]

15. Qin, Y.S.; Han, X.L.; Song, K.K.; Tian, Y.H.; Peng, C.X.; Wang, L.; Sun, B.A.; Wang, G.; Kaban, I.; Eckert, J. Local melting to design strong and plastically deformable bulk metallic glass composites. Sci. Rep. 2017, 7, 42518. [CrossRef]

16. Liu, Y.; Pang, S.; Li, H.; Hu, Q.; Chen, B.; Zhang, T. Formation and properties of Ti-based Ti-Zr-Cu-Fe-Sn-Si bulk metallic glasses with different $(\mathrm{Ti}+\mathrm{Zr}) / \mathrm{Cu}$ ratios for biomedical application. Intermetallics 2016, 72, $36-43$. [CrossRef]

17. Pang, S.; Liu, Y.; Li, H.; Sun, L.; Li, Y.; Zhang, T. New Ti-based Ti-Cu-Zr-Fe-Sn-Si-Ag bulk metallic glass for biomedical applications. J. Alloy. Compd. 2015, 625, 323-327. [CrossRef]

18. Yang, Y.J.; Fan, X.D.; Wang, F.L.; Qi, H.N.; Yue, Y.; Ma, M.Z.; Zhang, X.Y.; Li, G.; Liu, R.P. Effect of Nb content on corrosion behavior of Ti-based bulk metallic glass composites in different solutions. Appl. Surf. Sci. 2019, 471, 108-117. [CrossRef]

19. Weingarten, C.; Buchbinder, D.; Pirch, N.; Meiners, W.; Wissenbach, K.; Poprawe, R. Formation and reduction of hydrogen porosity during selective laser melting of AlSi10Mg. J. Mater. Process. Technol. 2015, 221, 112-120. [CrossRef]

20. Guo, M.; Gu, D.D.; Xi, L.X.; Du, L.; Zhang, H.M.; Zhang, J.Y. Formation of scanning tracks during Selective Laser Melting (SLM) of pure tungsten powder: Morphology, geometric features and forming mechanisms. Int. J. Refract. Met. Hard Mater. 2019, 79, 37-46. [CrossRef]

21. Yeh, J.; Chen, S.; Lin, S.; Gan, J.; Chin, T.; Shun, T.; Tsau, C.; Chang, S. Nanostructured High-Entropy Alloys with Multiple Principal Elements: Novel Alloy Design Concepts and Outcomes. Adv. Eng. Mater. 2004, 6, 299-303. [CrossRef]

22. Huo, L.S.; Zeng, J.F.; Wang, W.H.; Liu, C.T.; Yang, Y. The dependence of shear modulus on dynamic relaxation and evolution of local structural heterogeneity in a metallic glass. Acta Mater. 2013, 61, 4329-4338. [CrossRef]

23. Wang, W.H. The elastic properties, elastic models and elastic perspectives of metallic glasses. Prog. Mater. Sci. 2012, 57, 487-656. [CrossRef] 
24. Lu, Z.; Jiao, W.; Wang, W.H.; Bai, H.Y. Flow unit perspective on room temperature homogeneous plastic deformation in metallic glasses. Phys. Rev. Lett. 2014, 113, 045501. [CrossRef] [PubMed]

25. Turnbull, D.; Cohen, M.H. On the Free-Volume Model of the Liquid-Glass Transition. J. Chem. Phys. 1970, 52, 3038-3041. [CrossRef]

26. Song, S.X.; Nieh, T.G. Direct measurements of shear band propagation in metallic glasses-An overview. Intermetallics 2011, 19, 1968-1977. [CrossRef]

27. Schuh, C.A.; Nieh, T.G. A nanoindentation study of serrated flow in bulk metallic glasses. Acta Mater. 2003, 51,87-99. [CrossRef]

28. Drozdz, D.; Kulik, T.; Fecht, H.J. Nanoindentation studies of Zr-based bulk metallic glasses. J. Alloy. Compd. 2007, 441, 62-65. [CrossRef]

29. Wang, W.H.; Wang, R.J.; Yang, W.T.; Wei, B.C.; Wen, P.; Zhao, D.Q.; Pan, M.X. Stability of ZrTiCuNiBe bulk metallic glass upon isothermal annealing near the glass transition temperature. J. Mater. Res. 2002, 17, 1385-1389. [CrossRef]

30. Sun, Y.; Huang, Y.; Fan, H.; Wang, Y.; Ning, Z.; Liu, F.; Feng, D.; Jin, X.; Shen, J.; Sun, J.; et al. In vitro and in vivo biocompatibility of an Ag-bearing Zr-based bulk metallic glass for potential medical use. J. Non-Cryst. Solids 2015, 419, 82-91. [CrossRef]

31. Huang, Y.; Guo, Y.; Fan, H.; Shen, J. Synthesis of Fe-Cr-Mo-C-B amorphous coating with high corrosion resistance. Mater. Lett. 2012, 89, 229-232. [CrossRef]

32. Pang, S.J.; Shek, C.H.; Asami, K.; Inoue, A.; Zhang, T. Formation and corrosion behavior of glassy $\mathrm{Ni}-\mathrm{Nb}-\mathrm{Ti}-\mathrm{Zr}-\mathrm{Co}(-\mathrm{Cu})$ alloys. J. Alloy. Compd. 2007, 434-435, 240-243. [CrossRef]

33. Raicheff, R.; Zaprianova, V.; Gattef, E. Effect of structural relaxation on electrochemical corrosion behaviour of amorphous alloys. J. Mater. Sci. Lett. 1997, 16, 1701-1704. [CrossRef]

34. Gu, J.-L.; Shao, Y.; Zhao, S.-F.; Lu, S.-Y.; Yang, G.-N.; Chen, S.-Q.; Yao, K.-F. Effects of Cu addition on the glass forming ability and corrosion resistance of Ti-Zr-Be-Ni alloys. J. Alloy. Compd. 2017, 725, 573-579. [CrossRef]

35. Yang, Y.J.; Zhang, Z.P.; Jin, Z.S.; Sun, W.C.; Xia, C.Q.; Ma, M.Z.; Zhang, X.Y.; Li, G.; Liu, R.P. A study on the corrosion behavior of the in-situ Ti-based bulk metallic glass matrix composites in acid solutions. J. Alloy. Compd. 2019, 782, 927-935. [CrossRef]

(C) 2019 by the authors. Licensee MDPI, Basel, Switzerland. This article is an open access article distributed under the terms and conditions of the Creative Commons Attribution (CC BY) license (http://creativecommons.org/licenses/by/4.0/). 